\title{
Radiological profile of patients undergoing Chest X-ray and computed tomography scans during COVID-19 outbreak
}

\author{
Sohail Ahmed Khan ${ }^{1}$, Murli Manohar', \\ Maria Khan ${ }^{3}$, Samita Asad ${ }^{4}$, Syed Omair Adil ${ }^{5}$
}

\begin{abstract}
Background \& Objective: Radiology has played a significant role in the diagnosis and quantifying the severity of COVID 19 pulmonary disease. This study was conducted to assess patterns and severity of COVID-19 pulmonary disease based on radiological imaging.

Methods: A prospective observational study was conducted in a large tertiary care public sector teaching hospital of Karachi, Pakistan from June 2020 till August 2020. All confirmed and suspected COVID-19 patients referred for chest X-rays and computed tomography (CT) scans were evaluated along with RT-PCR results. Suspected patients were followed for RT-PCR. Radiological features and severity of imaging studies were determined.

Results: Of 533 patients in whom X-rays were performed, majority had severe/critical findings, i.e., $304(57.03 \%)$. Of 97 patients in whom CT scan was performed, mild/moderate findings were observed in $63(64.94 \%)$ patients. Of 472 patients with abnormal X-rays, majority presented with alveolar pattern 459 (97.2\%), bilateral lung involvement 453 (89.6\%), and consolidation 356 (75.4\%). Moreover, lobar predominance showed lower zone preponderance in $446(94.5 \%)$ patients. Of 88 patients with abnormal CT findings, ground-glass opacity (GGO) 87 (98.9\%) and crazy paving 69 (78.4\%) were the most common findings. An insignificantly higher association of PCR positive cases was observed with severe/critical X-rays (p-value 0.076) and CT scan findings ( $p$-value 0.431).

Conclusion: Most common patterns on CT scans were GGO and crazy paving. While on chest radiographs, bilateral lung involvement with alveolar pattern and consolidation were most common findings. On X-rays, majority had severe/critical whereas CT scan had mild/moderate findings.
\end{abstract}

KEYWORDS: COVID-19; Computed tomography; X-rays; Chest.

doi: https://doi.org/10.12669/pjms.37.5.4290

How to cite this:

Khan SA, Manohar M, Khan M, Asad S, Adil SO. Radiological profile of patients undergoing Chest X-ray and computed tomography scans during COVID-19 outbreak. Pak J Med Sci. 2021;37(5):1288-1294. doi: https://doi.org/10.12669/pjms.37.5.4290

This is an Open Access article distributed under the terms of the Creative Commons Attribution License (http://creativecommons.org/licenses/by/3.0), which permits unrestricted use, distribution, and reproduction in any medium, provided the original work is properly cited.

\section{INTRODUCTION}

COVID-19 pandemic has been devastating throughout the world and remains a challenge in terms of diagnosis and management. ${ }^{1-4}$ Although the current diagnostic criterion for COVID-19 is

Correspondence:

Dr. Sohail Ahmed Khan

Dow Institute of Radiology,

Dow University of Health Sciences,

Gulzar-e-Hijri, SUPARCO Road,

KDA Scheme 33, Karachi-75280, Pakistan.

Email: ahmedsohail.dr@gmail.com

* Received for Publication:

* Revision Received:

* Revision Accepted: *

February 17, 2021

April 20, 2021

April 29, 2021 the real-time reverse transcription-polymerase chain reaction (RT-PCR), ${ }^{5}$ radiology has also played a significant role in the diagnosis and quantifying the severity of COVID 19 pulmonary disease throughout the world.., 7 As per guidelines by the Radiological Society of North America (RSNA), imaging is only indicated in positive COVID-19 patients having worsening respiratory status and in suspected COVID-19 patients having moderate to severe symptoms with the unavailability of RT-PCR tests. ${ }^{8}$

X-rays and Computed Tomography (CT) became more prevalent globally in helping to increase awareness and track the progress of Covid-19 pulmonary disease. ${ }^{9-11}$ The disease profile evolved 
rapidly, as evident by literature, a spectrum of significant imaging findings was noted in asymptomatic patients and, on the other hand, critically ill patients with no significant radiological manifestations were seen. ${ }^{12,13}$ However, it has been noted that chest X-ray is less sensitive in detecting the early manifestations of pulmonary disease, although it can detect the disease in advanced stages. CT scan, on the other hand, can detect early parenchymal lung disease, disease progression, and alternative diagnoses. ${ }^{14}$ Due to the relative constraints of CT scanner availability, higher radiation dose, and decontamination procedure following imaging, patients are not routinely referred for CT scan. ${ }^{15}$ Chest X-ray is the initial imaging investigation in patients with respiratory symptoms; yet, much less has been written about it for COVID-19. ${ }^{16}$

This study was conducted to identify the role of radiological imaging in the assessment of disease severity in a cohort of the Pakistani population as no published study of such a large sample size was detected during data search for both CT and X-ray.

\section{METHODS}

This prospective observational study has been conducted at the Dow institute of Radiology, Dow University of Health Sciences from June 2020 to August 2020. Approval of the Ethical Review Board (Ref: IRB-1694/DUHS/Approval/2020, dated: 27 ${ }^{\text {th }}$ June 2020) was obtained; informed consent from all patients undergoing chest X-ray and CT scans was taken regarding the publication of their data while maintaining confidentiality.

Epi Info sample size calculator is used for the estimation of sample size taking confidence interval $99.9 \%$, margin of error 5\%, reported frequency of ground-glass opacities on CT lung $86 \% .{ }^{17}$ The estimated sample size came out to be 319 . However, a total of 596 patients were included, out of which 499 had a chest X-ray only, 63 had a chest CT scan only, and 34 patients had both chest X-ray and CT scans. Chest X-ray of all the suspected COVID-19 patients (having fever $>38^{\circ} \mathrm{C}$ with symptoms of lower respiratory tract illness like a cough or shortness of breath and history of traveling from abroad or contact with a RT-PCR positive COVID-19 patient within 14 days of onset of symptoms or with fever $>38^{\circ} \mathrm{C}$ with a severe acute respiratory illness like pneumonia or acute respiratory distress syndrome requiring hospitalization along with confirmed cases (RT-PCR positive) admitted in hospital isolation wards and intensive care units were obtained through portable X-ray machines. Both non-contrast imaging after volumetric like high resolution CT and contrast-enhanced CT chest were performed as per the primary physician's request. All X-rays and CT scans were done after using personal protective equipment and following the guidelines for safe exposure to limit cross-infection. Image Analysis: All cases were reported by two junior radiologists and two senior radiologists having more than 10 years of reporting experience. The presence of imaging features including consolidation, air space shadowing, and pleural effusions were noted in X-rays of all suspected and confirmed patients. CT images were classified predominantly as having ground-glass opacities, consolidations, cavitation, nodular opacities, crazy paving, pleural/pericardial effusions, and lymphadenopathy. Findings were further categorized into the zonal (X-ray) and lobar predominance (CT).

Radiological Scoring:

Chest X-ray severity score: Severity was measured through Radiographic Assessment of Lung Edema (RALE) criteria that includes no involvement, mild $(<25 \%)$ involvement, moderate $(25-50 \%)$ involvement, severe $(50-75 \%)$ involvement, critical $(>75 \%)$ involvement. ${ }^{18}$

CT scan chest severity score: Involvement of $0 \%$ lung was considered as none, $1-25 \%$ was considered as mild, $26-50 \%$ was considered as moderate, 51$75 \%$ was considered as severe, and $76-100 \%$ was considered as critical. ${ }^{19} \mathrm{X}$-ray and CT severity were further subcategorized into two groups: mild and moderate cases were merged and labeled as a minor group (having $<50 \%$ involvement). While severe and critical cases were merged and labeled as a major group ( $>50 \%$ involvement). A detailed clinical history was obtained from patients through a prestructured questionnaire. The epidemiological and clinical data including age, sex, traveling history, history of contact with RT-PCR positive patient, clinical symptoms including fever, cough, sputum, shortness of breath, diarrhea, body pain and chest pain, duration of symptoms, and comorbidities including hypertension, diabetes and chronic obstructive pulmonary disease was recorded. RTPCR of all the suspected radiological cases was followed, and the cases were finally grouped as positive or negative for COVID-19.

Statistical Analysis: SPSS version 21 was used for analysis. The mean \pm SD for age and onset days of COVID-19 symptoms was determined. Frequency and percentages were calculated for gender, history 
of travel, history of contact with a COVID-19 patient, symptoms, past medical history, CT chest, and $\mathrm{X}$-ray findings. A comparative analysis of groups of X-ray and CT severity with patients' demographic data and clinical characteristics and RT-PCR result was done. Inferential statistics were explored using Independent t-test, and Chi-square/Fisher-Exact test applied. p-value $\leq 0.05$ was considered as significant. Diagnostic accuracy of X-ray and CT scan was also calculated using PCR as gold standard.

\section{RESULTS}

Of 596 patients, the mean age was $54.58 \pm 13.64$ years. There were $414(69.5 \%)$ males and $182(30.5 \%)$ females. The mean onset of symptoms was 3.91 \pm 1.41 days. The cough was the most predominant symptoms observed in 544 (91.3\%), fever in 473 $(79.4 \%)$, shortness of breath in $442(74.2 \%)$, and body pain in $405(67.9 \%)$ patients. The frequency of comorbidities showed that hypertension was observed in $49(8.2 \%)$, diabetes in $27(4.5 \%)$, and COPD in $16(2.7 \%)$ patients.

X-ray findings were reported in 533 patients. Of these, normal X-ray findings were observed in 61 $(11.4 \%)$, mild in $58(10.9 \%)$, moderate in $110(20.6 \%)$, severe in 117 (19.6\%), and critical in 187 (35.1\%) patients. (Fig.1) Comparative analysis of severe/ critical findings on X-rays with demographic and clinical characteristics showed a significantly higher proportion of $\mathrm{X}$-ray severity in patients with shortness of breath $(\mathrm{p}$-value $<0.001)$ and chest pain (p-value 0.002). (Table-I)

CT scans were performed in 97 patients. Of these normal CT findings were observed in $9(9.3 \%)$, mild in $27(27.8 \%)$, moderate in $36(37.1 \%)$, severe in $20(20.6 \%)$, and critical in $5(5.2 \%)$ patients.

\begin{tabular}{|c|c|}
\hline \multicolumn{2}{|c|}{$\begin{array}{c}\text { Both X-rays and } \\
\text { CT scans performed } \\
(n=34)\end{array}$} \\
\hline $\begin{array}{l}\text { No severe/critical } \\
\text { findings on X-rays }\end{array}$ & $\begin{array}{c}\text { Severe/critical } \\
\text { - findings on X-rays }\end{array}$ \\
\hline$(n=03)$ & $(n=31)$ \\
\hline $\begin{array}{l}\text { Severe/critical } \\
\text { findings on CT }\end{array}$ & $\begin{array}{l}\text { Severe/critical } \\
\text { findings on CT }\end{array}$ \\
\hline $\begin{array}{c}\text { scan } \\
(\mathrm{n}=0,0 \%)\end{array}$ & $\begin{array}{c}\text { scans } \\
(\mathrm{n}=18,58.1 \%)\end{array}$ \\
\hline $\begin{array}{c}\text { No severe/critical } \\
\text { findings on CT scans }\end{array}$ & $\begin{array}{c}\text { No severe/critical } \\
\text { _ findings on CT scans }\end{array}$ \\
\hline$(n=3,100 \%)$ & $(n=13,41.9 \%)$ \\
\hline
\end{tabular}

Fig.1: Severity findings in patients with both $X$-ray and CT examinations $(n=34)$.
Comparative analysis of severe/critical findings on CT scans with demographic and clinical characteristics showed a significantly higher proportion of CT severity in patients with longer duration of symptoms ( $\mathrm{p}$-value 0.003), patients with the complaint of body pain (p-value 0.011), and travel history (p-value 0.042). (Table-I)

There were $34(5.70 \%)$ patients in whom both X-ray and CT examinations were performed. Of

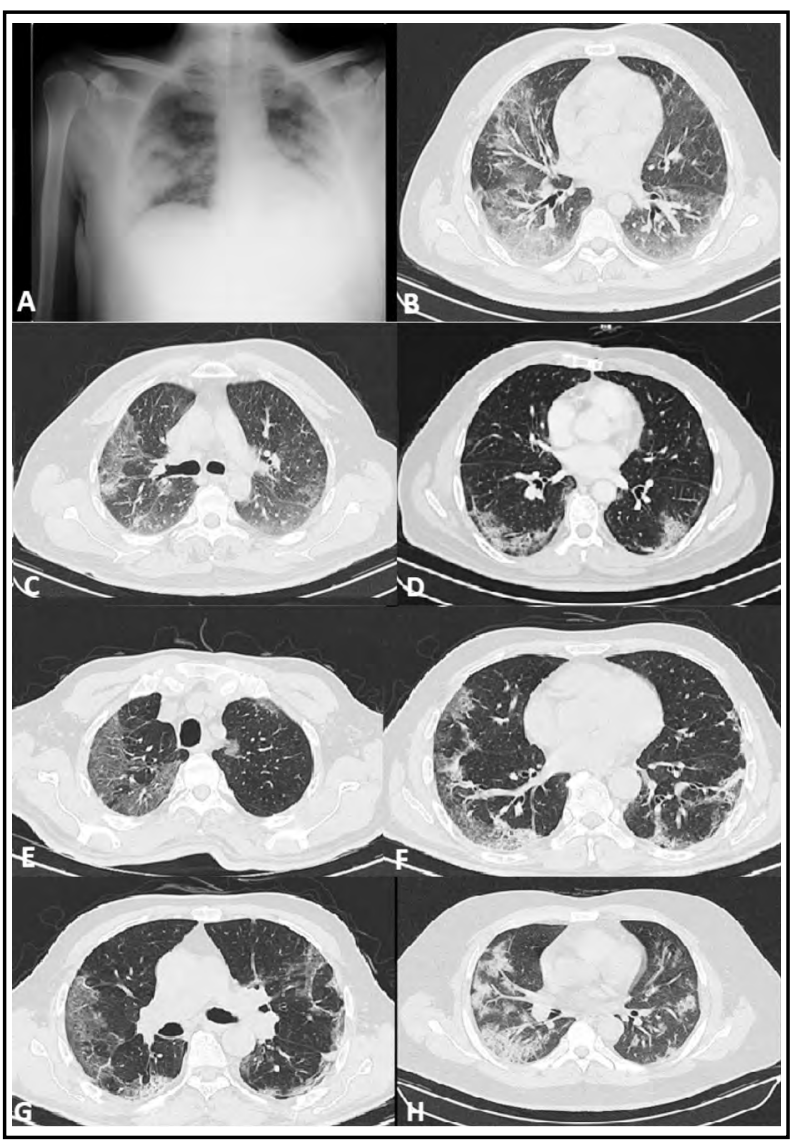

Fig.2: (A) Chest $\mathrm{X}$-ray supine view of a 45 years male patient with severe dyspnea showing bilateral mid and lower zone airspace shadowing with peripheral predilection. (B) HRCT chest lung window axial images of same patient showing bilateral peripheral subpleural areas of ground glass haze with lower lobe predominance. (C,D) CT chest contrast axial image in lung window showing subpleural ground glass haze, reticulation and crazy paving in lower lobes in a 65 years male patients with fever, cough and sore throat. (E-G) HRCT chest lung window axial images of a 60 years male patient with fever, cough, dyspnea and body aches showing bilateral ground glass haze and crazy paving in peripheral subpleural location of both lungs. (H) HRCT chest lund window image of a 48 years male patient with fever, dyspnea and body ache showing bilateral peripheral subpleural consolidations with minimal ground glass haze in both lungs. 
Sohail Ahmed Khan et al.

Table-I: Comparative analysis of X-ray and CT severity findings with demographic and clinical characteristics of the patients.

\begin{tabular}{|c|c|c|c|c|c|c|c|c|c|}
\hline & \multicolumn{2}{|c|}{$\begin{array}{l}\text { Severe/critical findings } \\
\text { on X-ray }(n=533)\end{array}$} & \multicolumn{4}{|c|}{$\begin{array}{l}\text { Severe/critical findings } \\
\text { on CT }(n=97)\end{array}$} & \multicolumn{3}{|c|}{$\begin{array}{l}\text { Severe/critical findings on } \\
\text { both X-ray } \mathcal{E} C T(n=34)\end{array}$} \\
\hline & Yes $(n=304)$ & No $(n=229)$ & p-value & Yes $(n=30)$ & No $(n=67)$ & $p$-value & $\begin{array}{c}\text { Yes } \\
(n=18)\end{array}$ & $\begin{array}{c}\text { No } \\
(n=16)\end{array}$ & $\begin{array}{c}p- \\
\text { value }\end{array}$ \\
\hline Age, years & $55.01 \pm 13.05$ & $54.28 \pm 14.48$ & $0.543^{€}$ & $58.33 \pm 10.14$ & $54.72 \pm 13.96$ & $0.205^{€}$ & & & \\
\hline \multicolumn{10}{|l|}{ Gender } \\
\hline Male & $211(69.4)$ & 157 (68.6) & \multirow{2}{*}{$0.834^{¥}$} & $21(70)$ & 48 (71.6) & \multirow{2}{*}{$0.869^{\#^{*}}$} & $12(66.7)$ & $11(68.8)$ & \multirow{2}{*}{0.897} \\
\hline Female & $93(30.6)$ & $72(31.4)$ & & $9(30)$ & $19(28.4)$ & & $6(33.3)$ & $5(31.3)$ & \\
\hline $\begin{array}{l}\text { The onset of } \\
\text { symptoms, } \\
\text { days }\end{array}$ & $4.21 \pm 1.33$ & $4.07 \pm 1.26$ & $0.217^{€}$ & $3.30 \pm 1.77$ & $2.40 \pm 1.06$ & $0.003^{€}$ & & & \\
\hline \multicolumn{10}{|l|}{ Symptoms } \\
\hline Fever & $211(69)$ & 175 (76.4) & $0.031^{¥}$ & $21(70)$ & $52(77.6)$ & $0.422^{¥}$ & 16 (88.9) & 14 (87.5) & 0.900 \\
\hline $\begin{array}{l}\text { Shortness of } \\
\text { breath }\end{array}$ & $254(83.6)$ & 141 (61.6) & $<0.001^{¥^{*}}$ & $23(76.7)$ & $53(79.1)$ & $0.788^{¥^{*}}$ & $16(88.9)$ & $13(81.3)$ & 0.530 \\
\hline Cough & $287(94.4)$ & $213(93)$ & $0.508^{¥}$ & $22(73.3)$ & $54(80.6)$ & $0.422^{¥}$ & $17(94.4)$ & $15(93.8)$ & 0.932 \\
\hline Sputum & $20(6.6)$ & $8(3.5)$ & $0.114^{¥}$ & $13(43.3)$ & $42(62.7)$ & $0.075^{¥}$ & $3(16.7)$ & $4(25)$ & 0.549 \\
\hline Diarrhea & $12(3.9)$ & $16(7)$ & $0.119^{¥}$ & $1(3.3)$ & $2(3)$ & $0.927^{\not}$ & $1(5.6)$ & $0(0)$ & 0.339 \\
\hline Chest Pain & $246(80.9)$ & $159(69.4)$ & $0.002^{z^{*}}$ & $19(63.3)$ & $37(55.2)$ & $0.455^{¥}$ & $14(77.8)$ & $16(100)$ & 0.045 \\
\hline Body Pain & $238(78.3)$ & $164(71.6)$ & $0.076^{¥}$ & $15(50)$ & $16(23.9)$ & $0.011^{¥}$ & 14 (77.8) & $14(87.5)$ & 0.458 \\
\hline \multicolumn{10}{|l|}{ Comorbidity } \\
\hline $\mathrm{HTN}$ & $15(4.9)$ & $19(8.3)$ & $0.116^{¥}$ & $6(20)$ & 12 (17.9) & $0.807^{\not}$ & 2 (11.1) & $1(6.3)$ & 0.618 \\
\hline Diabetes & $5(1.6)$ & $10(4.4)$ & $0.060^{¥}$ & $2(6.7)$ & $12(17.9)$ & $0.145^{¥}$ & $0(0)$ & $2(12.5)$ & 0.122 \\
\hline COPD & $5(1.6)$ & $6(2.6)$ & $0.433^{¥}$ & $1(3.3)$ & $4(6)$ & $0.587^{\not}$ & $18(100)$ & $16(100)$ & - \\
\hline $\begin{array}{l}\text { Travel His- } \\
\text { tory }\end{array}$ & $15(4.9)$ & $12(5.2)$ & $0.873^{¥}$ & 4 (13.3) & $5(7.5)$ & $0.042^{¥^{*}}$ & $2(11.1)$ & $1(6.3)$ & 0.618 \\
\hline $\begin{array}{l}\text { Contact His- } \\
\text { tory }\end{array}$ & $66(21.7)$ & $41(17.9)$ & $0.277^{\not}$ & $15(50)$ & $43(64.2)$ & $0.188^{¥}$ & $5(27.8)$ & $4(25)$ & 0.855 \\
\hline
\end{tabular}

${ }^{\epsilon}$ Independent t-test applied, ${ }^{*}$ Chi-square/Fisher-Exact test applied, ${ }^{*}$ p-value $\leq 0.05$.

these 34 patients, $31(91.2 \%)$ patients showed severe/critical findings on X-rays, and $3(8.82 \%)$ showed no severe/critical findings on X-rays. Of 31 patients in whom X-ray findings showed severe/ critical findings, only 18 (58.1\%) were found severe/ critical on CT scans whereas in 3 patients in whom X-ray findings showed no severe/critical findings, CT scans also showed no severe/critical findings in all these patients, i.e. 3 (100\%). (Fig.1)

Radiological profile of abnormal X-ray findings showed that of 472 patients in whom abnormality was observed, the majority of the patients were presented with an alveolar pattern, bilateral lung involvement, and consolidation, i.e. 459 (97.2\%), $453(89.6 \%)$, and 356 (75.4\%) respectively. Moreover, lobar predominance showed lower zone preponderance in $446(94.5 \%)$ patients. CT findings showed that out of 88 patients in whom abnormality was observed, ground-glass opacity (GGO), >50\% GGO, and crazy paving were observed in most of the patients, i.e. $87(98.9 \%), 68(77.3 \%)$, and 69 (78.4\%) respectively. (Table-II)

Diagnostic accuracy of X-ray showed sensitivity, specificity, PPV, and NPV as $88.87 \%, 66.67 \%$, $99.79 \%$, and $3.28 \%$ respectively. Similarly, diagnostic accuracy of CT scan was found to be $96.67 \%, 85.71 \%, 98.86 \%$, and $66.67 \%$ respectively. (Table-III).

X-ray findings showed an insignificantly higher proportion of PCR positive cases in whom severe/critical findings on X-rays were present as compared to those in whom severe/critical 
Table-II: Radiological Profile of abnormal X-ray and CT findings.

\begin{tabular}{|c|c|c|}
\hline & $n$ & $\%$ \\
\hline \multicolumn{3}{|c|}{ X-ray Radiological Profile $(n=472)$} \\
\hline \multicolumn{3}{|l|}{ Lung Findings } \\
\hline Alveolar Pattern & 459 & 97.2 \\
\hline Consolidation & 356 & 75.4 \\
\hline Bilateral lung involvement & 453 & 89.6 \\
\hline Pleural Effusion & 14 & 3 \\
\hline \multicolumn{3}{|l|}{ Lobar Predominance } \\
\hline Upper Zone & 1 & 0.2 \\
\hline Lower Zone & 446 & 94.5 \\
\hline Both & 17 & 3.6 \\
\hline \multicolumn{3}{|l|}{ CT Radiological Profile $(n=88)$} \\
\hline \multicolumn{3}{|l|}{ Lobar Predominance } \\
\hline Right Upper Lobe & 76 & 86.4 \\
\hline Right Middle Lobe & 63 & 71.6 \\
\hline Right Lower Lobe & 86 & 97.7 \\
\hline Left Upper Lobe & 74 & 84.1 \\
\hline Left Lower Lobe & 86 & 97.7 \\
\hline \multicolumn{3}{|l|}{ Predominant Distribution } \\
\hline Peripheral & 70 & 79.5 \\
\hline Perihilar & 2 & 2.3 \\
\hline No Predominance & 16 & 18.2 \\
\hline \multicolumn{3}{|l|}{ CT Findings } \\
\hline Ground Glass Opacity (GGO) & 87 & 98.9 \\
\hline Consolidation & 48 & 54.5 \\
\hline$>50 \%$ GGO & 68 & 77.3 \\
\hline$>50 \%$ Consolidation & 11 & 12.5 \\
\hline Crazy paving & 69 & 78.4 \\
\hline Cavitation & 0 & 0 \\
\hline Nodules & 4 & 4.5 \\
\hline Pleural Effusion & 4 & 4.5 \\
\hline Pericardial Effusion & 0 & 0 \\
\hline Enlarged Nodes & 1 & 1.1 \\
\hline
\end{tabular}

findings on X-rays severity were not present, i.e. $304(100 \%)$ and $226(98.7 \%)$ respectively, p-value 0.076. Similarly, CT findings showed an insignificantly higher proportion of PCR positive cases in whom severity was present as compared to those in which severity was not present, i.e.
$29(96.7 \%)$ and $61(91.0 \%)$ respectively, p-value 0.431 .

\section{DISCUSSION}

This study was conducted in a large public sector tertiary care hospital specified by the government for COVID-19 with designated three isolation wards and three ICUs. Moreover, in this hospital, investigations for the COVID-19 patients were offered free of cost, therefore we were able to cater the needs of a large population. The findings of the study identified the occurrence of ground-glass opacity as the most common finding in CT scans of COVID-19 pulmonary disease. (Fig.2) This is coinciding with the outcomes of previous studies done in China, America, Europe, and Pakistan. ${ }^{20-23}$ It is present in almost all abnormal CT scans making it an essential diagnostic feature. A study by Li, Y. and Xia, L confirmed the absence of ground-glass opacity in COVID 19 positive patients to be a rare occurrence. ${ }^{24}$ Crazy paving was the second most common finding, in contrast to a much lower reported frequency in the previously published studies in China, Italy, and also in other cities of Pakistan. ${ }^{25-27}$ A similar high frequency was reported by Li $\mathrm{K}$ et al., who compared the chest CT features associated with severe and critical COVID-19 pulmonary disease with mild cases and stated that crazy paving is associated with a higher severity of disease and another study suggested that it could be used as a marker for disease progression. ${ }^{28}$ Therefore, the other studies which showed lower frequency could be assumed to be conducted in a less severely affected population and with smaller sample size. Consolidation was the next most common finding when it was compared with ground-glass opacity, more than half of the scans had ground-glass opacity. All these features were most commonly seen bilaterally in the subpleural peripheral location of the lower lobes, synchronizing with the findings of various studies. ${ }^{16,29}$ In this study, pleural effusion, lymphadenopathy, cavitation, and pericardial effusion were rarely noted, as was seen in previous literature. In this context, Bai and his colleagues have concluded that these particular findings were found to be more prevalent in viral pneumonia other than COVID-19 pulmonary disease. ${ }^{30}$

In terms of severity, most of the patients who presented for CT scan showed moderate severity, and the patients who presented for X-rays showed critical severity.There could be few reasons for this; firstly, the utility of CT scan as a screening tool was discouraged by leading radiological societies. ${ }^{8}$ and 
Table-III: Diagnostic accuracy of X-ray and CT scans taking PCR findings as gold standard.

\begin{tabular}{|c|c|c|c|c|c|c|c|}
\hline \multicolumn{8}{|c|}{ PCR Finding } \\
\hline Abnormal X-ray & Yes & No & Sensitivity & Specificity & $P P V$ & $N P V$ & $\begin{array}{c}\text { Overall Diagnostic } \\
\text { Accuracy }\end{array}$ \\
\hline Yes & 471 & 1 & \multirow{2}{*}{$88.87 \%$} & \multirow{2}{*}{$66.67 \%$} & \multirow{2}{*}{$99.79 \%$} & \multirow{2}{*}{$3.28 \%$} & \multirow{2}{*}{$88.74 \%$} \\
\hline No & 59 & 2 & & & & & \\
\hline \multicolumn{8}{|c|}{ Abnormal CT } \\
\hline Yes & 577 & 10 & \multirow{2}{*}{$96.67 \%$} & \multirow{2}{*}{$85.71 \%$} & \multirow{2}{*}{$98.86 \%$} & \multirow{2}{*}{$66.67 \%$} & \multirow{2}{*}{$95.88 \%$} \\
\hline No & 9 & 0 & & & & & \\
\hline
\end{tabular}

was indicated in moderate to severe cases only as mentioned previously. Secondly, portable X-rays, as opposed to $\mathrm{CT}$, were more commonly being carried out in severely ill patients admitted in ICUs (including those on mechanical ventilation). Due to the constraints of logistics of shifting to the radiology department and rigorous time-consuming decontamination measures that followed. This may have had an impact on results.

Regarding the PCR negative patients undergoing the X-ray, none were present in the major group. However, more than half were found to be in the major group on the CT scan, suggesting that the CT scan is highly sensitive for the detection of disease in the presence of negative PCR. ${ }^{31}$ This can be attributed to the fact that PCR has a high falsenegative rate, and the unavailability of testing kits in early outbreak restricted the prompt diagnosis of infected patients. Therefore, the role of the CT scan was recognized as a diagnostic tool. In a low resource country like Pakistan, CT scan was mostly advised by physicians in highly suspected patients. On the other hand, for severely ill and confirmed cases, the X-rays were used as a diagnostic tool due to cost-effectiveness and logistic problems, as discussed earlier.

Strength and Limitations of the study: The findings of this study can be highlighted in the light of certain limitations. Firstly, in the current study, follow-up of patients was not carried out. Therefore, disease outcome was not assessed. Secondly, the patients were not categorized into groups according to the duration of symptoms to study the various imaging stages of this disease as present in previous literature. ${ }^{32-34}$ Moreover, some patients may have received therapy in the form of antimicrobial drugs or steroids, which may have altered the disease severity at the time of imaging and this factor was not taken into account. The strength of this study was a larger sample size including both X-ray and CT scans. To the best of our knowledge no such study in Pakistan has been conducted so far that has included both radiological modalities, evaluating data for COVID-19 pulmonary disease for this large number of patients. Further studies are recommended to evaluate the disease pattern over time with the help of follow-up imaging to determine patient outcomes.

\section{CONCLUSION}

In our cohort, most of the patients undergoing chest X-ray showed severe lung involvement, whereas most of the other patients undergoing CT scan chest revealed mild to moderate lung disease.

\section{Abbreviations:}

COVID-19 = Coronavirus disease 2019

CT $=$ Computed Tomography

GGO = Ground-Glass Opacity

RALE $=$ Radiographic Assessment of Lung Edema

RSNA = Radiological Society of North America

RT $\mathbf{P C R}=$ Reverse Transcriptase - Polymerase Chain Reaction

Conflict of Interest: The authors have no conflicts of interest.

\section{REFERENCES}

1. Rajabally YA, Goedee HS, Attarian S, Hartung HP. Management challenges for chronic dysimmune neuropathies during the COVID-19 pandemic. Muscle Nerve. 2020;62:34-40. doi: $10.1002 /$ mus.26896

2. Gates B. Responding to Covid-19-a once-in-a-century pandemic? N Engl J Med. 2020;382:1677-1679. doi: 10.1056/NEJMp2003762

3. Livingston E, Bucher K. Coronavirus disease 2019 (COVID-19) in Italy. JAMA 2020;323:1335. doi:10.1001/jama.2020.4344

4. Yancy CW. COVID-19 and African Americans. JAMA. 2020;323:1891-1892. doi: 10.1001/jama.2020.6548

5. Zayet S, Kadiane-Oussou NJ, Royer PY, Toko L, Gendrin $\mathrm{V}$, Klopfenstein T. Coronavirus disease 2019: New things to know! J Med Virol. 2020 Oct;92(10):1767-1768. doi: 10.1002/ jmv.25874 
6. Zhang JJ, Cao YY, Tan G, Dong X, Wang BC, Lin J, et al. Clinical, radiological, and laboratory characteristics and risk factors for severity and mortality of 289 hospitalized COVID-19 patients. Allergy. 2021;76(2):533-550. doi: 10.1111/all.14496

7. Nair A, Rodrigues JC, Hare S, Edey A, Devaraj A, Jacob J, et al. A British Society of Thoracic Imaging statement: considerations in designing local imaging diagnostic algorithms for the COVID-19 pandemic. Clin Radiol. 2020;75:329-334. doi: 10.1016/j.crad.2020.03.008

8. Aljondi R, Alghamdi S. Diagnostic value of imaging modalities for covid-19: Scoping review. J Med Internet Res. 2020;22:e19673. doi: 10.2196/19673.

9. Rubin GD, Ryerson CJ, Haramati LB, Sverzellati N, Kanne JP, Raoof S, et al. The Role of Chest Imaging in Patient Management During the COVID-19 Pandemic: A Multinational Consensus Statement From the Fleischner Society. Chest. 2020;158:106-116. doi: 10.1016/j.chest.2020.04.003

10. Ai T, Yang Z, Hou H, Zhan C, Chen C, Lv W, et al. Correlation of Chest CT and RT-PCR Testing for Coronavirus Disease 2019 (COVID-19) in China: A Report of 1014 Cases. Radiology. 2020;296(2):E32-E40. doi: 10.1148/radiol.2020200642.

11. Fang $\mathrm{Y}$, Zhang $\mathrm{H}$, Xie J, Lin M, Ying L, Pang P, et al. Sensitivity of Chest CT for COVID-19: Comparison to RT-PCR. Radiology. 2020;296(2):E115-E117. doi: 10.1148/radiol.2020200432

12. Sverzellati N, Milanese G, Milone F, Balbi M, Ledda RE, Silva M. Integrated Radiologic Algorithm for COVID-19 Pandemic. J Thorac Imaging. 2020;35:228-233. doi: 10.1097/ RTI.0000000000000516

13. Yang W, Yan F. Patients with RT-PCR-confirmed COVID-19 and Normal Chest CT. Radiology. 2020;295(2):E3. doi: 10.1148/ radiol.2020200702

14. Chung M, Bernheim A, Mei X, Zhang N, Huang M, Zeng X, et al. CT imaging features of 2019 novel coronavirus (2019-nCoV) Radiology. 2020;295:202-207. doi: 10.1148/radiol.2020200230

15. Driggin E, Madhavan MV, Bikdeli B, Chuich T, Laracy J, BiondiZoccai G, et al. Cardiovascular considerations for patients, health care workers, and health systems during the COVID-19 pandemic. J Am Coll Cardiol. 2020;75(18):2352-2371. doi: 10.1016/j.jacc.2020.03.031

16. Mossa-Basha $M$, Medverd J, Linnau K, Lynch JB, Wener MH, Kicska G, et al. Policies and Guidelines for COVID-19 Preparedness: Experiences from the University of Washington. Radiology. 2020;296(2):E26-E31. doi: 10.1148/radiol.2020201326

17. Ng MY, Lee EY, Yang J, Yang F, Li X, Wang H, et al. Imaging profile of the COVID-19 infection: radiologic findings and literature review. Radiology: Cardiothoracic Imaging. 2020;2:e200034. doi: 10.1148/ryct.2020200034

18. Smith DL, Grenier JP, Batte C, Spieler B. A Characteristic Chest Radiographic Pattern in the Setting of COVID-19 Pandemic Radiology: Cardiothoracic Imaging. 2020;2:e200280. doi: 10.1148 /ryct.2020200280

19. Wong HY, Lam HY, Fong AH, Leung ST, Chin TW, Lo CS, et al. Frequency and distribution of chest radiographic findings in COVID-19 positive patients. Radiology. 2020:201160. doi: 10.1148/radiol.2020201160

20. Zhou S, Wang Y, Zhu T, Xia L. CT features of coronavirus disease 2019 (COVID-19) pneumonia in 62 patients in Wuhan China. Am J Roentgenol. 2020;214:1287-1294. doi: 10.2214/ AJR.20.22975

21. Chowell G, Mizumoto K. The COVID-19 pandemic in the USA: what might we expect? Lancet. 2020;395:1093-1094. doi: 10.1016/S0140-6736(20)30743-1

22. Galván Casas C, Catala AC, Carretero Hernández G, Rodríguez Jiménez P, Fernández Nieto D, Rodríguez-Villa Lario A, et al. Classification of the cutaneous manifestations of COVID-19: A rapid prospective nationwide consensus study in Spain with 375 cases. Br J Dermatol. 2020;183:71-77. doi: 10.1111/bjd.19163

23. Khan S, Khan M, Maqsood K, Hussain T, Zeeshan M. Is Pakistan prepared for the COVID-19 epidemic? A questionnaire-based survey. J Med Virol. 2020;92:824-832. doi: 10.1002/jmv.25814
24. Li Y, Xia L. Coronavirus disease 2019 (COVID-19): role of chest CT in diagnosis and management. Am J Roentgenol. 2020;214:1280-1286. doi: 10.2214/ AJR.20.22954

25. Caruso D, Zerunian M, Polici M, Pucciarelli F, Polidori T, Rucci C, Guido G, Bracci B, De Dominicis C, Laghi A. Chest CT Features of COVID-19 in Rome, Italy. Radiology. 2020;296(2):E79-E85. doi: 10.1148/radiol.2020201237

26. Zu ZY, Jiang MD, Xu PP, Chen W, Ni QQ, Lu GM, Zhang LJ. Coronavirus Disease 2019 (COVID-19): A Perspective from China. Radiology. 2020;296(2):E15-E25. doi: 10.1148/ radiol.2020200490

27. Khaliq M, Raja R, Khan N, Hanif H. An Analysis of HighResolution Computed Tomography Chest Manifestations of COVID-19 Patients in Pakistan. Cureus. 2020;12:e9373. doi: 10.7759 /cureus.9373

28. Li K, Wu J, Wu F, Guo D, Chen L, Fang Z, Li C. The clinical and chest $\mathrm{CT}$ features associated with severe and critical COVID-19 pneumonia. Invest Radiol. 2020;55:327-331. doi: 10.1097/ RLI.0000000000000672

29. Shi H, Han X, Jiang N, Cao Y, Alwalid O, Gu J, et al. Radiological findings from 81 patients with COVID-19 pneumonia in Wuhan, China: A descriptive study. Lancet Infect Dis. 2020;20:425-434. doi: 10.1016/S1473-3099(20)30086-4

30. Bai HX, Hsieh B, Xiong Z, Halsey K, Choi JW, Tran TM, et al. Performance of radiologists in differentiating COVID-19 from viral pneumonia on chest CT. Radiology. 2020;296:E46-54. doi: 10.1148/radiol.2020200823

31. Majidi H, Niksolat F. Chest CT in patients suspected of COVID-19 infection: A reliable alternative for RT-PCR. Am J Emerg Med. 2020;S0735-6757:30244-8. doi: 10.1016/j.ajem.2020.04.016

32. Vancheri SG, Savietto G, Ballati F, Maggi A, Canino C, Bortolotto C, et al. Radiographic findings in 240 patients with COVID-19 pneumonia: time-dependence after the onset of symptoms. Eur Radiol. 2020;30:6161-6169. doi: 10.1007/s00330-020-06967-7

33. Pan F, Ye T, Sun P, Gui S, Liang B, Li L, et al. Time course of lung changes on chest $\mathrm{CT}$ during recovery from 2019 novel coronavirus (COVID-19) pneumonia. Radiology 2020;295:715-721

34. Bernheim A, Mei X, Huang M, Yang Y, Fayad ZA, Zhang N, et al. Chest CT findings in coronavirus disease-19 (COVID-19) Relationship to duration of infection. Radiology 2020;295:200463. doi: $10.1148 /$ radiol.2020200463

\section{Authors' Contributions:}

SAK, SOA, MM, MK: Conception and design of the study.

SOA: Data collection, analysis, and interpretation.

$S A, M K, M M$ : Manuscript writing.

$S A K$ : Critical Review and final approval of the manuscript.

SOA: Responsible and accountable for the accuracy or integrity of the work.

\section{Authors:}

1. Sohail Ahmed Khan, Assistant Professor,

2. Murli Manohar,

Instructor,

3. Maria Khan,

Instructor,

4. Samita Asad, Resident,

5. Syed Omair Adil, Lecturer Biostatistics, School of Public Health, Dow University of Health Sciences, Karachi, Pakistan.

1-4: Dow Institute of Radiology,

Dow University of Health Sciences, Karachi, Pakistan. 